NBER WORKING PAPER SERIES

\title{
FAIRNESS AND REDISTRIBUTION:
}

U.S. VERSUS EUROPE

\author{
Alberto Alesina \\ George-Marios Angeletos \\ Working Paper 9502 \\ http://www.nber.org/papers/w9502
}

\author{
NATIONAL BUREAU OF ECONOMIC RESEARCH \\ 1050 Massachusetts Avenue \\ Cambridge, MA 02138 \\ February 2003
}

This project was initiated by a lively discussion we had with Olivier Blanchard and Xavier Gabaix in February 2002. For helpful discussions and comments, we thank Daron Acemoglu, Robert Barro, Roland Benabou, Olivier Blanchard, Peter Diamond, Glenn Ellison, Ed Glaeser, Jon Gruber, Eliana La Ferrara, Roberto Perotti, Thomas Philippon, Jim Poterba, Andrei Shleifer, Guido Tabellini, Ivan Werning, and seminar participants at MIT, Warwick, Trinity College, Dublin, ECB, and IGIER Bocconi. Arnaud Devleeschauer provided excellent research assistance. The views expressed herein are those of the authors and not necessarily those of the National Bureau of Economic Research.

(C2003 by Alberto Alesina and George-Marios Angeletos. All rights reserved. Short sections of text not to exceed two paragraphs, may be quoted without explicit permission provided that full credit including notice, is given to the source. 
Fairness and Redistribution: U.S. versus Europe

Alberto Alesina and George-Marios Angeletos

NBER Working Paper No. 9502

February 2003

JEL No. D7, E6, H1

\begin{abstract}
$\underline{\text { ABSTRACT }}$
Different beliefs about how fair social competition is and what determines income inequality, influence the redistributive policy chosen democratically in a society. But the composition of income in the first place depends on equilibrium tax policies. If a society believes that individual effort determines income, and that all have a right to enjoy the fruits of their effort, it will chose low redistribution and low taxes. In equilibrium effort will be high, the role of luck limited, market outcomes will be quite fair, and social beliefs will be self-fulfilled. If instead a society believes that luck, birth, connections and/or corruption determine wealth, it will tax a lot, thus distorting allocations and making these beliefs self-sustained as well. We show how this interaction between social beliefs and welfare policies may lead to multiple equilibria or multiple steady states. We argue that this model can contribute to explain US vis a vis continental European perceptions about income inequality and choices of redistributive policies.
\end{abstract}

\author{
Alberto Alesina \\ Department of Economics \\ Harvard University \\ Cambridge, MA 02138 \\ and NBER \\ aalesina@harvard.edu
}

\author{
George-Marios Angeletos \\ Department of Economics \\ MIT \\ 50 Memorial Drive, E52-251 \\ Cambridge, MA 02142 \\ angelet@mit.edu
}




\section{A. Alesina and G.M. Angeletos}

\section{Introduction}

Pre-tax inequality is higher in the United States than in continental Western European countries ("Europe" in short). For example, the Gini coefficient in the pre-tax income distribution in the United States is 38.5 against 29.1 in Europe. Nevertheless, redistributive policies are more extensive in Europe. The income tax structure is more progressive in Europe, and the overall size of government is about 50 per cent larger in Europe than in the United States (that is, about 30 versus about 45 per cent of GDP). The largest difference is indeed in transfers and other social benefits, where Europeans spend about twice as much as Americans. Moreover, the public budget is only one of the means to support the poor; an important dimension of redistribution is legislation, and in particular the regulation of labor and product markets, which are much more intrusive in Europe than in the United States. ${ }^{1}$

The coexistence of high pre-tax inequality and low redistribution is prima facia inconsistent with either the Meltzer-Richard paradigm of redistribution, or the Mirrlees paradigm of social insurance. Instead, the difference in the political support for redistribution appears to reflect, at least in part, a difference in social perceptions regarding the fairness of market outcomes and the underlying sources of income inequality. More Americans than Europeans believe that poverty is due to bad choices or lack of effort rather than bad luck or social injustice; Europeans view poverty as a trap from which it is hard to escape. Americans perceive wealth and success as the outcome of individual talent, effort, and entrepreneurship; Europeans attribute a larger role to luck and connections. According to the World Values Survey, 71 per cent of Americans versus 40 per cent of Europeans believe that the poor could become rich if they just tried hard enough; and a larger proportion of Europeans than Americans believe that luck and connections, rather than hard work, determine economic success.

The effect of social beliefs about how fair market outcomes are on actual policy choices is not limited to a comparison of the United States and Europe. Figure 1 shows a strong positive correlation between a country's GDP share of social spending and its' belief that

\footnotetext{
${ }^{1}$ Alesina and Glaeser (2003) document extensively the sharp differences in redistribution between the United States and Europe.
} 


\section{FAIRNESS AND REDISTRIBUtion}

luck and connections determine income. This correlation is easy to interpret if political outcomes reflect a social desire for fairness. But, why do different counties have so different perceptions about the fairness of market outcomes? Who is right, the Americans who think that effort determines success, or the Europeans who think that it is mostly luck?

\section{[insert Figure 1 here]}

In this paper we show that, in equilibrium, it can be the case that luck is more important in one place, while effort is more important in another place, even if there are no intrinsic differences in economic fundamentals between the two places. Both Americans and Europeans can thus be correct in their beliefs about what are the sources of income inequality. The key element in our analysis is the idea of "social justice" or "fairness". With these terms we capture a social preference for reducing the degree of inequality induced by luck and unworthy activities, while rewarding individual talent and effort. Since the society can not tell apart the part of an individual's income that is due to luck and unworthy activities (the "noise" in the income distribution) from the part that is due to talent and effort (the "signal"), the socially optimal level of redistribution is decreasing in the "signal-to-noise ratio" in the income distribution (the ratio of justifiable to unjustifiable inequality). Higher taxation, on the other hand, distorts private incentives and leads to lower effort and investment. As a result, the equilibrium signal-to-noise ratio in the income distribution is itself decreasing in the level of redistribution. This interaction between the level of redistribution and the composition of inequality may lead to multiple equilibria. In the one equilibrium, taxes are higher, individuals invest and work less, and inequality is lower; but a relative large share of total income is due to luck, which in turn makes high redistribution socially desirable. In the other equilibrium, taxes are lower, individuals invest and work more, and inequality is higher; but a larger fraction of income is due to effort rather than luck, which in turn sustains the lower tax rates as an equilibrium.

We should be clear from the outset that we do not mean to argue that "fundamentals" between Europe and the United States are identical, or that the multiplicity of equilibria we identify in our benchmark model is the only source of the politico-economic differences across the two sides of the Atlantic. Our multiple-equilibria mechanism should be 


\section{A. Alesina and G.M. Angeletos}

interpreted more generally as a propagation mechanism that can help explain large and persistent differences in social outcomes on the basis of small differences in underlying fundamentals, initial conditions, or shocks.

How the different historical experiences of the two places (which by now are largely hard-wired in the different cultures of the two places) may explain the different attitudes and policies towards inequality, is indeed in the heart of our argument. In a dynamic variant of our model, we consider the implications of the fact that wealth is transmitted from one generation to the next through bequests or other shorts of parental investment. The distribution of wealth in one generation now depends, not only on the contribution of effort and luck in that generation, but also on the contribution of effort and luck in all previous generations. As a result, how fair the wealth distribution is in one period, and what is the optimal redistributive policy in that period, depend on the history of policies and outcomes in all past periods. We conclude that the differences in perceptions, attitudes, and policies towards inequality (or more generally towards the market mechanism) across the two sides of the Atlantic can be understood on the basis of different initial conditions and different historical coincidences. ${ }^{2}$

Following Rawls (1971) and Mirrlees (1971), fairness has been modeled before as a demand for insurance. However, the standard Mirrlees paradigm does not incorporate a distinction between justifiable and unjustifiable inequality, which is the heart of our approach. ${ }^{3}$ Other papers have discussed multiple equilibria in related models. In Piketty (1995), multiple beliefs are possible because agents form their beliefs only on the basis of their personal experience and can not learn the true costs and benefits of redistribution. In Benabou and Tirole (2002), multiple beliefs are possible because agents find it optimal to deliberately bias their own perception of the truth so as to offset another bias, namely procrastination. ${ }^{4}$ Finally, in Benabou (2000), multiplicity originates in imperfect credit

\footnotetext{
${ }^{2}$ Alesina and Glaeser (2003) describe how a transatlantic difference in the evolution of the welfare state dates back to its origin.

${ }^{3}$ See, however, Amador, Angeletos and Werning (2003) and the concluding remark in Section 6.

${ }^{4}$ Benabou and Tirole (2002) endogenize the choice of political ideology and more specifically the choice of whether to "believe to a just world". Their work shares some common motivation with ours, but their contribution developed independently and is rather orthogonal to ours. In their model, but not in ours, people suffer from procrastination and lack of self control. At the same time, they have the ability to
} 


\section{FAIRNESS AND REDistribUtion}

and insurance markets. In our paper, instead, multiplicity originates merely in the social desire to implement fair economic outcomes and survives even when beliefs are fully unbiased, agents know the truth, and there are no important differences in capital markets or other economic fundamentals.

The rest of the paper is organized as follows. Section 2 reviews some evidence on fairness and redistribution, which motivate our modelling approach. Section 3 introduces the basic static model. Section 4 analyzes the interaction of economic and voting choices and derives the two regimes as multiple static equilibria. Section 5 introduces intergenerational links and derives the two regimes as multiple steady states. Section 6 concludes. All formal proofs are in the Appendix.

\section{Fairness and Redistribution: a few facts}

Our crucial assumption is that agents expect the society to reward individual effort and hard work and the government to intervene and correct market outcomes to the extent that outcomes are driven by luck. The available empirical evidence is supportive of this assumption. ${ }^{5}$

Fairness and preferences for redistribution. The effect of social beliefs about what determines income (luck or effort) on actual policy choices is not limited to a comparison of the United States versus Europe. Figure 1, which is reproduced from Alesina Glaeser and Sacerdote (2001), shows a strong positive correlation between the share of social spending over GDP and the percentage of respondents to the World Values Survey who think that income is determined mostly by luck. As Table 1 shows, this correlation is robust to controlling for the Gini coefficient, per-capita GDP, and continent dummies. It is also robust to controlling for two political variables, the nature of the electoral system

repress past experiences and thereby distort their own beliefs regarding what are the returns to individual effort. Given that the ex-post optimal level of effort is inefficiently low from an ex-ante perspective, people find it optimal ex ante to maintain a more "rosy" picture about the benefits of effort in order to "deceive" themselves into putting more effort ex post.

${ }^{5}$ Complementary is also the evidence that fairness concerns affect labor relations (Kahneman, Knetsch, and Thaler, 1986; Agell and Lundborg, 1995; Bewley, 1999). 


\section{A. Alesina and G.M. Angeletos}

and Presidential versus parliamentary regime, which may influence the size of transfers, as argued by Persson and Tabellini (2003). ${ }^{6}$

\section{[insert Table 1 here]}

The impact of fairness perceptions is evident, not only in aggregate outcomes, but also in individual attitudes. The World Values Survey asks the respondent whether he identifies himself as being on the left of the political spectrum. We take this "leftist political orientation" as a proxy for favoring redistribution and government intervention. We then regress this variable against the individual's belief about what determines income together with a series of individual- and country-specific controls. As Table 2 shows, the belief that luck determines income has a strong and significant effect on the probability of being leftist. Further evidence is provided by Fong (2002), Corneo and Gruner (2002), and Alesina and La Ferrara (2003). Using the General Social Survey for the United States, the latter study finds that individuals who think that income is determined by luck, connections, and family history rather than individual effort, education, and ability, are much more favorable to redistribution, even after controlling for an exhaustive set of other individual characteristics.

\section{[insert Table 2 here]}

Experimental evidence. $\quad$ Fehr and Schmidt (2001) provide an extensive review of the experimental evidence on altruism, reciprocity, and fairness. In dictator games, people give a small portion of their endowment to others, even though they could keep it all. In ultimatum games, people are ready to suffer a monetary loss themselves just to punish behavior that is considered "unfair". In gift exchange games, on the other hand, people are willing to suffer a loss in order to reward actions that they perceive as generous or fair. Finally, in public good games, cooperators tend to punish free-riders. These findings

\footnotetext{
${ }^{6}$ The correlation looses some significance if one controls for the population share of the old, which is because the size of pensions depends heavily on this variable. However, the pension system is much more redistributive in Europe than in the United States (Alesina and Glaeser, 2003). Also the correlation between transfer payments and beliefs in luck remains very strong once we exclude pensions. More details are available in the working paper version of the paper.
} 


\section{FAIRNESS AND REDISTRIBUTION}

are very robust to changes in the size of monetary stakes or the background of players. In short, there is plenty experimental evidence that people have an innate desire for fairness, and are ready to punish unfair behavior. What is more, the existing evidence rejects the hypothesis that altruism takes merely the form of absolute inequity aversion. People instead appear to desire equality relative to some reference point, namely what they consider as a "fair" outcome.

Further support in favor of our concept of fairness is provided by the evidence that experimental outcomes are sensitive to whether initial endowments are assigned randomly or as a function of previous achievement. In ultimatum games, Hoffman and Spitzer (1985) and Hoffman et al. (1998) find that proposers are more likely to make unequal offers, and responders are less likely to reject unequal offers, when the proposers have outscored the respondents in a preceding trivia quiz, and even more if they have been explicitly told that they have "earned" their roles in the ultimatum game on the basis of their preceding performance. In double auction games, Ball et al. (1996) report a similar sensitivity of the division of surplus between buyers and sellers on whether market status is random or earned. Finally, in a public good game where groups of people with unequal endowments vote over two alternative contribution schemes, Clark (1998) finds that members of a group are more likely to vote for the scheme that effectively redistributes less from the rich to the poor members of the same group, when initial endowments depend on previous relative performance in a general-knowledge quiz rather than been randomly assigned.

Psychologists, sociologists and political scientists have also stressed the importance of a sense of fairness in the private, social and political life of men. People enjoy great satisfaction when they know (or believe) that they live in a just world, where hard work and good behavior ultimately pay off. ${ }^{7}$ In short, it is a fundamental conviction that one should get what he deserves and, conversely, that one should deserve whatever he gets.

\footnotetext{
${ }^{7}$ What is more, people may actually distort their perception or interpretation of reality in order to maintain their belief to a just world; see Lerner (1982) and Benabou and Tirole (2002).
} 


\section{A. Alesina And G.M. Angeletos}

\section{The Basic Model}

Consider a non-overlapping generation model, in which each generation consists of a large number of agents (a $[0,1]$ continuum), who live for two periods. In each period of life, agents engage in a productive activity, which can be interpreted as labor supply, accumulation of physical or human capital, entrepreneurship, etc.. The tax and redistributive policy is set in the middle of their life. (These assumptions about the timing of economic and political decisions are made only to ensure that part of agents' wealth is fixed when the policy is chosen.) Agents are not altruistic towards future generations and consume all their disposable income at the end of their life. As there are no links across generations, the economy is essentially static, and we can characterize politico-economic outcomes in one generation without reference to any other generation. (We consider inter-generational links later, in Section 5.)

\subsection{Heterogeneity, technologies, and preferences}

The investment and productive activities of the first period of life require effort. Life-cycle income, or wealth, is the combined outcome of inherent talent, investment during the first period of life, effort during the second period of life, and luck:

$$
y_{i}=A_{i}\left[\alpha k_{i}+(1-\alpha) e_{i}\right]+\eta_{i}
$$

$y_{i}$ denotes income, $k_{i}$ investment in the first period of life, and $e_{i}$ effort in the second period of life. $^{8} \alpha \in(0,1)$ is a technological constant, which can be interpreted as the share of income that is sunk when the tax rate is set. ${ }^{9}$ Finally, $\eta_{i}$ is i.i.d. noise, which we interpret as random luck or the effect of socially unworthy activities, such as corruption, rent seeking, political subversion, theft, fraud, etc. ${ }^{10}$

\footnotetext{
${ }^{8}$ If we interpret $k_{i}$ as a form of human capital, $k_{i}$ and $e_{i}$ are likely to be complements; such complementarities would complicate the algebra but would not matter for our results. Also, the possibility that productivity and human capital reflect family background, is examined in Section 5 .

${ }^{9}$ As shown later on, $\alpha>0$ is essential for the possibility of multiple equilibria, whereas $\alpha<1$ simply ensures that $\tau=1$ is never an equilibrium.

${ }^{10}$ See the working-paper version of this article for a vairant of our model where exogenous "luck" is replaced by an endogenous rent-seeking activity.
} 


\section{FAIRNESS AND REDistribUtion}

Consumption, or disposable income, is given by

$$
c_{i}=(1-\tau) y_{i}+G,
$$

where $\tau$ is the flat-rate tax imposed on wealth and $G$ is a lump sum transfer. This redistributive scheme is widely used in the literature following Romer (1975) and Meltzer and Richard (1981), because it is the simplest one to model. The qualitative nature of our message is not unduly sensitive to the precise nature of this scheme. ${ }^{11}$

Individual preferences are given by

$$
U_{i}=u_{i}-\gamma \Omega,
$$

where $u_{i}$ represents the private utility from own consumption, investment, and effort choices, $\Omega$ represents the common disutility generated by unfair social outcomes (to be defined below), and $\gamma \geq 0$ parametrizes the strength of the social demand for fairness. To simplify, we specify

$$
u_{i}=V_{i}\left(c_{i}, k_{i}, e_{i}\right)=c_{i}-\frac{1}{2 \beta_{i}}\left[\alpha k_{i}^{2}+(1-\alpha) e_{i}^{2}\right]
$$

The first term represents the utility of consumption. The second term represents the costs of first-period investment and second-period effort. $\beta_{i}$ parametrizes the willingness to postpone consumption and work hard: a low $\beta_{i}$ captures impatience or laziness, a high $\beta_{i}$ captures "care for the future" or "love for work". If agents suffered from procrastination and hyperbolic discounting, $\beta_{i}$ could also be interpreted as the degree of self control. ${ }^{12}$ Finally, the coefficients $\alpha / 2$ and $(1-\alpha) / 2$ are merely a normalization.

\subsection{Fairness, government, and equilibrium}

Following the evidence in Section 2 that most people share a common conviction that one should get what he deserves and deserve what he gets, we define

$$
\Omega=\int_{i}\left(u_{i}-\widehat{u}_{i}\right)^{2},
$$

\footnotetext{
${ }^{11}$ See the remarks in Sections 4.1 and 6 .

${ }^{12}$ In that case, we would need to distinguish between ex ante and ex post preferences. For example, we could let $\beta_{i}=1$ for all $i$ ex ante, whereas $\beta_{i} \leq 1$ for all $i$ and $\operatorname{Var}\left(\beta_{i}\right)>0$ ex post. For an elegant model where the anticipation of procrastination affects also the choice of ideology, see Benabou and Tirole (2002).
} 


\section{A. Alesina and G.M. Angeletos}

where $u_{i}$ denotes the actual level of utility and $\widehat{u}_{i}$ denotes the "fair" level of utility. The latter is defined as the utility the agent deserves on the basis of his talent and effort, namely $\widehat{u}_{i}=V_{i}\left(\widehat{c}_{i}, k_{i}, e_{i}\right)$ where

$$
\widehat{c}_{i}=\widehat{y}_{i}=A_{i}\left[\alpha k_{i}+(1-\alpha) e_{i}\right] .
$$

represent the "fair" levels of consumption and income. Similarly, the residual $y_{i}-\widehat{y}_{i}=\eta_{i}$ measures the "unfair" component of income.

Because utility is quasilinear in consumption, $u_{i}-\widehat{u}_{i}=c_{i}-\widehat{c}_{i}$ for every $i$, and therefore $\Omega=\int_{i}\left(c_{i}-\widehat{c}_{i}\right)^{2}$. Together with (2) and (5), this gives

$$
\Omega=\int_{i}\left\{\left[(1-\tau) y_{i}+\tau \bar{y}\right]-\widehat{y}_{i}\right\}^{2} .
$$

In the absence of government intervention, $\Omega$ would reduce to $\Omega=\int_{i}\left(y_{i}-\widehat{y}_{i}\right)^{2}$, thus measuring how unfair is the pre-tax income distribution; in the presence of government intervention, $\Omega$ measures how unfair economic outcomes remain after redistribution.

The government chooses the tax rate $\tau \in[0,1]$ and the level of spending $G$, subject to the budget constraint $G=\tau \bar{y}$, where $\bar{y} \equiv \int_{i} y_{i}$ is the average income in the population. Because fairness is a public good, it is not essential for our results how exactly individual preferences are aggregated into political choices about redistribution: No matter what is the weight of different agents in the political process, the concern for fairness will always be reflected in political choices. To be consistent with the related literature, we assume that the preferences of the government coincide with those of the median voter. ${ }^{13}$

For future reference, we let $\delta_{i} \equiv A_{i}^{2} \beta_{i}$, assume $\operatorname{Cov}\left(\delta_{i}, \eta_{i}\right)=0$, and denote $\sigma_{\delta}^{2} \equiv$ $\operatorname{Var}\left(\delta_{i}\right), \sigma_{\eta}^{2} \equiv \operatorname{Var}\left(\eta_{i}\right)$, and $\Delta \equiv \delta_{m}-\bar{\delta} \geq 0$, where $\delta_{m}$ and $\bar{\delta}$ are the median and the mean of $\delta_{i}$. There two sources of support for redistribution in the model. One is the standard "selfish" redistribution a la Meltzer and Richard (1981), which arises if and only $\Delta>0$. The other is the "altruistic" redistribution originating in the desire to correct for the effect of luck on income, which arrises if and only if $\gamma>0$.

Definition. The economy is parametrized by $\mathcal{E} \equiv\left(\Delta, \gamma, \alpha, \sigma_{\delta}, \sigma_{\eta}\right)$. An equilibrium is a tax rate $\tau$ and a collection of individual plans $\left\{k_{i}, e_{i}\right\}_{i \in[0,1]}$ such that $(i)$ the plan

\footnotetext{
${ }^{13}$ As shown in the Appendix, $\max _{i}\left\{\delta_{i}\right\} \leq 2 \bar{\delta}$ actually suffices for preferences to be single-picked in $\tau$ and thus for the median-voter theorem to apply.
} 
$\left(k_{i}, e_{i}\right)$ maximizes the utility of agent $i$ for every $i$, and $(i i)$ the tax rate $\tau$ maximizes the utility of the median agent.

\section{Equilibrium Analysis}

\subsection{Fairness and singal extraction}

Suppose that $y_{i}-\widehat{y}_{i}$ is independent of $\widehat{y}_{i}$; this will turn to be true in equilibrium if and only if $\eta_{i}$ is independent of $\delta_{i}$, which we have assumed for simplicity. Then, from (6) we obtain social injustice as a weighted average of the "variance decomposition" of income inequality:

$$
\Omega=\tau^{2} \operatorname{Var}\left(\widehat{y}_{i}\right)+(1-\tau)^{2} \operatorname{Var}\left(y_{i}-\widehat{y}_{i}\right),
$$

where $\operatorname{Var}$ denotes variance in the cross-section of agents. Note that the weights depend on the level of redistribution, namely $\tau$. If minimizing $\Omega$ were the only policy goal, taxation were not distortionary, and the income distribution were exogenous, the equilibrium tax rate would be given simply by:

$$
\frac{1-\tau}{\tau}=\frac{\operatorname{Var}\left(\widehat{y}_{i}\right)}{\operatorname{Var}\left(y_{i}-\widehat{y}_{i}\right)} .
$$

The right-hand side represents a "signal-to-noise ratio" in the income distribution: The "signal" is the fair component of income and the "noise" is the effect of luck. As the goal of redistribution is to correct for the effect of luck on income, the optimal tax rate is decreasing is this signal-to-noise ratio.

Remark. The implicit assumption that motivates the restriction of policy to a linear income (or wealth) tax is that $\left(y_{i}, c_{i}\right)$ are publicly observable, but $\left(A_{i}, \beta_{i}, \eta_{i}\right)$ and thus $\left(k_{i}, e_{i}, \widehat{y}_{i}, \widehat{c}_{i}\right)$ are private information to agent $i$. That is, the society observes the total income of each agent, but can not tell whether this income is the fruits of talent and effort or the outcome of pure luck (or corruption, rent seeking, etc.). As a result, the society necessarily faces the singal-extraction problem identified above when seeking to determine the optimal level of redistribution. This property is likely to survive even if we allowed for a general non-linear tax a la Mirrlees. ${ }^{14}$

\footnotetext{
${ }^{14}$ See Amador, Angeletos, and Werning (2003) and the concluding remark in Section 6.
} 
A. Alesina and G.M. Angeletos

\subsection{The equilibrium signal-to-noise ratio}

Consider the investment and effort decisions of agent $i$. He chooses $k_{i}$ and $e_{i}$ so as to maximize

$$
u_{i}=(1-\tau) A_{i}\left[\alpha k_{i}+(1-\alpha) e_{i}\right]+G-\frac{1}{2 \beta_{i}}\left[\alpha k_{i}^{2}+(1-\alpha) e_{i}^{2}\right]
$$

taking $\tau$ and $G$ as given. Since agents choose $k_{i}$ before $\tau$ is fixed, first-period investment is a function of the anticipated tax rate and is sunk when the actual tax rate is chosen. On the other hand, agents choose second-period effort $e_{i}$ ex post, contingent on the realized tax and the investment they made before. To distinguish the anticipated tax rate from the realized one, we henceforth denote the former by $\tau_{e}$ and the latter by $\tau$. (Of course, $\tau_{e}=\tau$ in any perfect-foresight equilibrium, but we adopt the different notation for the shake of clarity.)

The first-order conditions with respect to $k_{i}$ and $e_{i}$ imply

$$
k_{i}=\left(1-\tau_{e}\right) \beta_{i} A_{i} \quad \text { and } \quad e_{i}=(1-\tau) \beta_{i} A_{i} .
$$

Substituting into (5), we conclude

$$
\widehat{y}_{i}=\left[1-\alpha \tau_{e}-(1-\alpha) \tau\right] \delta_{i}
$$

where $\delta_{i} \equiv \beta_{i} A_{i}^{2}$. Therefore, exogenous heterogeneity in either talent $\left(A_{i}\right)$ or impatience and laziness $\left(\beta_{i}\right)$ translates to endogenous heterogeneity in in the fair component of income $\left(\widehat{y}_{i}\right)$. It follows that the equilibrium signal-to-noise ratio in the income distribution is

$$
\frac{\operatorname{Var}\left(\widehat{y}_{i}\right)}{\operatorname{Var}\left(y_{i}-\widehat{y}_{i}\right)}=\left[1-\alpha \tau_{e}-(1-\alpha) \tau\right]^{2} \frac{\sigma_{\delta}^{2}}{\sigma_{\eta}^{2}},
$$

where $\sigma_{\delta}^{2} \equiv \operatorname{Var}\left(\delta_{i}\right) \equiv \operatorname{Var}\left(\beta_{i} A_{i}^{2}\right)$ and $\sigma_{\eta}^{2} \equiv \operatorname{Var}\left(\eta_{i}\right)$. We conclude that, in equilibrium, the signal-to-noise ratio in the income distribution is decreasing in the tax rate, reflecting the distortionary effect of taxation.

Remark. The critical features of the model that generate equilibrium multiplicity are (i) that the optimal tax rate is decreasing in the signal-to-noise ratio and (ii) that the equilibrium signal-to-noise ratio is in turn decreasing in the tax rate. To deliver the second feature, we have chosen a simple specification for income in which "luck" enters additively 


\section{FAIRNESS AND REDISTRIBUtion}

and thus does not interact with effort or investment. Nevertheless, this simplification per se is not essential. What is essential is that higher taxes, by distorting effort and investment, result to a reduction in the level of justifiable inequality relative to the level of unjustifiable inequality. For this to be true, it is necessary and sufficient that higher taxes distort the fair sources of income more than the unfair sources, ${ }^{15}$ which we believe to be a very plausible hypothesis. Actually, if "luck" represents the output of tax evasion, corruption, and political connections, it is even likely that higher government intervention increases the absolute contribution of "luck", in which case the negative effect of the tax rate on the signal-to-noise ratio is reinforced. Finally, note that, in our model, the role of heterogeneity in $A_{i}$ and/or $\beta_{i}$ is to generate endogenous variation in the "fair" level of income. Endogenizing the concept of fairness, and understanding why societies consider some sources of inequality as justifiable and others as unfair, is an exciting direction for future research, but it is beyond the scope of this paper.

\subsection{The optimal policy}

The optimal policy maximizes the utility of the median voter. Assuming that luck has zero mean and median, the median voter, denoted by $i=m$, is an agent with characteristics $\delta_{m}=$ median $\left(\delta_{i}\right)$ and $\eta_{m}=0$. Letting $\Delta \equiv \bar{\delta}-\delta_{m}$ and normalizing $\delta_{m}=2$, the utility of the median voter in equilibrium reduces to ${ }^{16}$

$$
U_{m}=\left(1-\alpha \tau_{e}^{2}\right)-(1-\alpha) \tau^{2}+\left[1-\alpha \tau_{e}-(1-\alpha) \tau\right] \tau \Delta-\gamma \Omega
$$

The first and second terms in (13) capture the welfare losses due to the distortion of first-period investment and second-period effort, respectively. The third term measures the net transfer the median voter enjoys from the tax system, reflecting the fact that a positive tax rate effectively redistributes from the mean to the median of the income distribution. This term introduces a "selfish" motive for redistribution as in Meltzer and Richard (1981). The last term instead captures the "altruistic" motive originating in the

\footnotetext{
${ }^{15}$ For example, if income were $y_{i}=A_{i}\left[\alpha k_{i}+(1-\alpha) e_{i}\right]+\eta_{i}\left[\alpha k_{i}+(1-\alpha) e_{i}\right]^{\phi}$, the signal-to-noise ratio would decrease with the tax rate if and only if $\phi<1$.

${ }^{16}$ See the Appendix for the derivation of (13).
} 


\section{A. Alesina and G.M. Angeletos}

social concern for fairness. From (7) and (11), the equilibrium value of $\Omega$ is

$$
\Omega=\tau^{2}\left[1-\alpha \tau_{e}-(1-\alpha) \tau\right]^{2} \sigma_{\delta}^{2}+(1-\tau)^{2} \sigma_{\eta}^{2}
$$

where $\sigma_{\delta}^{2}=\operatorname{Var}\left(\delta_{i}\right)$ and $\sigma_{\eta}^{2}=\operatorname{Var}\left(\eta_{i}\right)$. Note that $\Omega$ depends on both $\tau_{e}$ and $\tau$. The negative dependence on $\tau_{e}$ reflects the fact that the anticipation of high taxation, by distorting first-period incentives, results to a large relative contribution of luck to income. The dependence on $\tau$ reflects a similar distortion of second-period incentives, but also the property that, keeping the pre-tax income distribution constant, more redistribution may correct for the effect of luck, thus obtaining a fairer distribution of after-tax disposable income. Finally, note that that $\tau_{e}$ is taken as given when $\tau$ is set, reflecting the fact that the agents' first-period investments are sunk. ${ }^{17}$ We conclude:

Proposition 1 When the ex-ante anticipated policy is $\tau_{e}$, the ex-post optimal policy is $\tau=f\left(\tau_{e} ; \mathcal{E}\right)$, where

$$
\begin{aligned}
& f\left(\tau_{e} ; \mathcal{E}\right) \equiv \arg \min _{\tau \in[0,1]}\left\{(1-\alpha) \tau^{2}+\tau^{2}\left(1-\alpha \tau_{e}-(1-\alpha) \tau\right)^{2} \gamma \sigma_{\delta}^{2}\right. \\
& \left.+(1-\tau)^{2} \gamma \sigma_{\eta}^{2}-\tau\left[1-\alpha \tau_{e}-(1-\alpha) \tau\right] \Delta\right\} .
\end{aligned}
$$

If $\gamma=\Delta=0$, then $f=0$. If $\Delta>0$ but $\gamma=0$, then $f>0$ and $\partial f / \partial \Delta>0$, but $\partial f / \partial \sigma_{\delta}=$ $\partial f / \partial \sigma_{\eta}=0$ and $\partial f / \partial \tau_{e}<0$. Finally, if $\gamma>0$, then $f>0$ and $\partial f / \partial \sigma_{\eta}>0$ necessarily; $\partial f / \partial \sigma_{\delta}<0$ and $\partial f / \partial \Delta>0$, unless both $\sigma_{\eta}$ and $\tau_{e}$ are too high; and $\partial f / \partial \tau_{e}>1$ for low $\tau_{e}$ when $\gamma$ and $\alpha$ are sufficiently high.

The intuition of these results is simple. If there is neither a concern for fairness $(\gamma=0)$, nor a difference between the mean and the median of the income distribution $(\Delta=0)$, the optimal tax is zero, as redistribution has only costs and no benefits from the perspective of the median voter. When the median is poorer than the mean $(\Delta>0)$, the MeltzerRichard effect kicks in, implying that the optimal tax rate is positive and increasing in $\Delta$. Nevertheless, as long as the there is no demand for fairness $(\gamma=0)$, the optimal tax remains independent of the sources of income inequality. Moreover, the ex-post optimal policy is decreasing in the ex-ante anticipated policy, as a higher distortion of first-period

\footnotetext{
${ }^{17}$ In other words, the median voter lacks commitment. In Sections 4.5 and 5, we explain why commitment is irrelevant for our results once intergenerational links are introduced.
} 


\section{FAIRNESS AND REDISTRIBUTION}

incentives reduces the income difference between the mean and the median and therefore also reduces the benefit of redistribution from the perspective of the median voter.

Things are quite different when the society desires fair economic outcomes $(\gamma>0)$. The society then seeks a positive level of redistribution in order to correct for the undesirable effect of luck on income inequality. As a result, the optimal tax is positive even if the median and the mean of the population coincide $(\Delta=0)$. The optimal tax then trades less efficiency for more fairness. As $\sigma_{\eta}$ increases, more of the observed income inequality originates in luck, which implies a higher optimal tax rate. The opposite consideration holds for higher $\sigma_{\delta}$, as this implies a larger relative contribution of ability and effort in income inequality. Finally, the relationship between $\tau_{e}$ and $\tau$ is generally non-monotonic. To understand this non-monotonicity, note that an increase in $\tau_{e}$ has an unambiguous adverse effect on the fairness of the income distribution, as it distorts first-period incentives. An increase in $\tau$, instead, has two opposing effects. On the one hand, like in the case of $\tau_{e}$, a higher $\tau$ reduces the "fair" component of income variation, because it distorts second-period incentives. On the other hand, a higher $\tau$ redistributes more from the poor to the rich and may thus "correct" for the effect of luck. When $\tau_{e}$ is small, the second effect dominates; $\tau$ increases with $\tau_{e}$ in order to expand redistribution and thus "correct" for the relatively larger effect of luck. When instead $\tau_{e}$ is high, the first effect dominates; $\tau$ falls with $\tau_{e}$ in order to encourage more effort and thus "substitute" for the adverse effect of a higher $\tau_{e}$.

\subsection{Multiple equilibria}

In equilibrium, expectations must be validated, which means $\tau_{e}=\tau$. The equilibrium set thus coincides with the set of fixed points of the function $f$. We have shown that the optimal level of redistribution is decreasing in the signal-to-noise ratio in the income distribution, reflecting the demand for fairness, and that the signal-to-noise ratio in turn is decreasing in the level of redistribution, reflecting the distortionary effect of taxation. We now establish that this interaction between the policy and the composition of income inequality may lead to multiple equilibria. 


\section{A. Alesina and G.M. Angeletos}

Proposition 2 An equilibrium always exists and corresponds to any fixed point of $f$, where $f$ is given by (15). If $\gamma=0$, there is a unique equilibrium, in which $\tau \in[0,1)$ and $\tau$ is increasing in $\Delta$ and independent of $\sigma_{\delta}$ and $\sigma_{\eta}$. If instead $\gamma>0$, there genericly exist multiple equilibria. In any stable equilibrium, the tax rate is $\tau \in(0,1)$, necessarily increasing in $\sigma_{\eta}$, and decreasing in $\sigma_{\delta}$ and increasing in $\Delta$, unless both $\sigma_{\eta}$ and $\tau$ are too high. Finally, the equilibrium with the lowest tax is the one with the highest inequality but also the highest singnal-to-noise ratio.

Therefore, if there is no (or little) social concern for fairness, there is a unique equilibrium, like in the standard Meltzer-Richard framework. But if $\gamma$ is sufficiently high, the economy is prone to multiple equilibria. The possibility of multiple equilibria is illustrated in Figure 2. ${ }^{18}$ The solid curve depicts the best-response function (15). Note that, if $\gamma$ were close to zero, this curve would be globally decreasing, and thus would necessarily intersect only once with the 45 -degree line. But now that $\gamma$ is sufficiently high, this curve has first an increasing portion, which opens the door to multiple equilibria. Indeed, the curve intersects three times with the $45^{\circ}$ line. The extreme two intersection points ( $U S$ and $E U)$ represent stable equilibria, while the middle one represents an unstable equilibrium, which we disregard. ${ }^{19}$ In point $E U$, the anticipation of high taxes induces agents to exert little effort in the first period. This in turn implies that the bulk of income heterogeneity is due to luck and makes it ex post optimal for society to undertake large redistributive programs, thus vindicating initial expectations. In point $U S$, instead, the anticipation of low taxes induces agents to exert high effort and implies that income variation is mostly the outcome of heterogeneity in talent and effort, which in turn makes low redistribution self-sustained in the political process. What is more, the level of inequality (as measured by the total variance of income) is lowest in $E U$, but the decomposition of inequality (as measured by the signal-to-noise ratio) is fairest in $U S$, which explains why more inequality

\footnotetext{
${ }^{18}$ The example is only illustrative and claims no quantitative value; it assumes $\gamma=1, \Delta=0, \alpha=1 / 2$, $\sigma_{\delta}=2.5$, and $\sigma_{\eta}=1$.

${ }^{19}$ Stability is defined in the usual manner: Let $f^{(n)}$ be the $n$-th order best-responce itteration; that is, $f^{(1)}=f$ and $f^{(n+1)}=f^{(n)} \circ f$ for any $n \geq 1$. A fixed point $\tau=f(\tau)$ is locally stable if and only if, for some $\varepsilon>0$ and any $x \in(\tau-\varepsilon, \tau+\varepsilon), \lim _{n \rightarrow \infty} f^{(n)}(x)=\tau$. Given differentiability, $f^{\prime}(\tau) \in(-1,+1)$ implies local stability, whereas $f^{\prime}(\tau) \notin[-1,+1]$ implies local instability.
} 


\section{FAIRNESS AND REDISTRIBUtion}

may come together with lower taxes.

\section{[insert Figure 2 here]}

As long as there is a sufficiently strong social demand for fairness and the undesirable impact of luck is neither too large nor too small as compared to the heterogeneity in talent and willingness to work, a high- and a low-tax regime are likely to coexist. On the other hand, if $\sigma_{\eta} / \sigma_{\delta}$ were so large that the effect of luck always dominated the effect of talent and effort in shaping the income distribution, then only the high-tax regime would

survive. Such a situation is illustrated by the upper dashed line in Figure 2. Finally, if either $\gamma$ of $\sigma_{\eta} / \sigma_{\delta}$ were very small, so that there is either little demand for fairness or little luck to correct, then only the low-tax regime would survive. Such a situation is illustrated by the lower dashed lined in Figure 2.

The comparative statics with respect to $\Delta$ are also intuitive. Consider first the case that $\Delta$ is sufficiently close to zero, in which case the altruistic motive originating in fairness dominates the selfish motive a la Meltzer and Richard. $f$ then increases with $\Delta$, implying that any stable fixed point of $f$ is locally increasing in $\Delta$. This reflects simply the fact that, the poorer the median voter is relatively to the mean, the higher the incentive to redistribute. As $\Delta$ increases, the optimal tax rate trades less of the public good (fairness) for more of the private good (self-interest redistribution). When $\Delta$ is sufficiently large, so that the selfish motive dominates, only the high-tax regime survives. But otherwise, the possibility of multiple equilibria remains.

\subsection{Comments}

The pure Meltzer-Richard model predicts that more inequality is correlated with more redistribution. Pure inequity aversion would predict a similar positive correlation. However, the evidence suggests a negative or null correlation between inequality and redistributive effort (e.g., Perotti, 1996; Alesina, Glaeser and Sacerdote, 2001). Our model can deliver such a negative correlation even after controlling for exogenous fundamentals: In the example of Figure 2, $U S$ has both a lower $\tau$ and a higher $\operatorname{Var}\left(y_{i}\right)$ than $E U$, simply because lower tax distortions generate higher but also more justifiable levels of income inequality. 


\section{A. Alesina and G.M. Angeletos}

The prediction that higher redistribuition should be correlated with higher belief that income inequality is unfair is clearly consistent with the data, as discussed in Section 2. But, what about the prediction that higher tax distortions should be correlated with lower levels of effort and investment? As we noted before, tax distortions are much higher in Europe; the income tax is much more progressive and the total tax burden is about 50 per cent higher than in the United States. At the same time, hours worked are much lower in Europe. In 2001, the average worked time per employee was about 1200 hours in Europe as compared to 1600 in the United States. Given the lower labor participation rate in Europe, the difference becomes even more striking when measured per person rather than per employee. Prescott (2003) computes an effective marginal tax on labor income that properly accounts for consumption taxes and social security contributions. This measure turns to be about 50 per cent lower in the United States than in France and Germany. Prescott also notes how the divergence of hours worked in Europe and in the United States accelerated over time together with the divergence of tax rates across the Atlantic. He thus concludes that differences in effective tax rates explains differences in labor supply across the two continents. ${ }^{20}$ Certainly, the higher regulation of labor markets in Europe also contributes to lower working hours; but regulation is just another distortionary instrument societies use for the purpose of improving the fairness of market outcomes. ${ }^{21}$ Also consistent with a distortionary effect of taxation is the observation that growth rates and various measures of investment in intangible capital are higher in the United States. The United States spend 2.8 per cent of GDP in R\&D, while the 15 EU countries spend 1.9 per cent (OECD data, 2001). Moreover, the fraction of this investment which is private (not government sponsored) is double in the United States. The percentage of college-educated individuals is 37.3 in the United States as compared to 18.8 in Europe (OECD data, 2001, individulas between the age of 25 and 64). This

\footnotetext{
${ }^{20}$ The elasticity of the labor supply that Prescott (2003) needs in order to attribute all of the difference in the working hours to taxes is on the high side of the range obtained by other studies; but, if not all, certainly a good portion of the difference in hours worked can be attributed to taxes.

${ }^{21}$ In addition to these measurable effects of taxation and regulation, there may be other, more subtle disincentive effects of the welfare state; these may involve changes in social norm that disengage individuals from market activities, as argued by Lindbeck, Nyberg and Weibull (1999) in theory and by Lindbeck et al (1994) as an explanation of the effects of the welfare state in Sweden.
} 


\section{FAIRNESS AND REDISTRIBUTION}

difference is even more striking if one considers that, in most European countries, college education is publicly provided and largely financed by general government revenues. Moreover, the skill premium in wages (the return to human capital) is also much higher in the United States according to any measure. For example, Table 1 in the recent survey by Acemoglu (2003) reports that the skill premium of college graduates relative to high-school graduates is at least 50 per cent higher in the United States that in Europe. ${ }^{22}$ In short, relative to Europeans, Americans work more, invest more in intangible capital, obtain higher rewards, and are taxed less.

The two equilibria in Figure 2 can easily be ranked from the perspective of the median voter: The one with lower taxes is superior, because there are less distortions, more investment, and more aggregate income; and because income inequality originates relatively more in ability than in luck, a socially desirable outcome. Poorer agents, however, may clearly prefer the high-tax equilibrium, as it redistributes more from the rich to the poor. Also, the high-tax equilibrium provides more insurance against the risk of being born with low talent or low willingness to work and thus may be preferred behind the veil of ignorance (that is, before the idiosyncratic shocks are realized and the agents learn their position in the income distribution).$^{23}$

Finally, it is of course unrealistic to think that an economy could "jump" from one regime to another by simply revising equilibrium expectations from one day to another. In the next section, we consider a dynamic variant of our model, in which history determines what beliefs the society holds and what redistributive policies it selects. The two regimes then re-emerge as multiple steady states along a unique equilibrium path. Similarly, whereas only the low-tax regime would survive in the static economy if the society could credibly commit on its tax policies before agents make their early-in-life investment choices, such commitment has little bite in the dynamic economy, where the wealth distribution is largely determined by policies and outcomes in earlier generations.

\footnotetext{
${ }^{22}$ For a discussion of how a larger supply of college graduates and a higher skill premium can coexist, see Acemoglu (1998)

${ }^{23}$ Risk aversion can be introduced by re-specifying preferences as $U_{i}=\Psi\left(u_{i}-\gamma \Omega\right)$, where $\Psi$ is an increasing and strictly concave function. Since every agent $i$ knows $\left(A_{i}, \beta_{i}, \eta_{i}\right)$ when he makes his choices, the equilibrium analysis goes through exactly as before, but the ranking of the two equilibria behind the veil of ingnorance depends on the concavity of $\Psi$.
} 


\section{$5 \quad$ Intergenerational Links and History Dependence}

One important determinant of wealth and success in life is being born in a wealthy family. To explore this issue, we now introduce intergenerational wealth transfers and parental investment (e.g., bequests, education, status, etc.) that link individual income to family history. ${ }^{24}$ Since we want to concentrate on the effect of history rather than self-fulfilling expectations, we abstract from investment choices made within a generation before the tax is set. The optimal policy is then uniquely determined in any given generation, but it depends on the decomposition of wealth in all previous generations. Finally, to keep the analysis as smooth as possible, we work out a dynamic model in which the steady-state analysis turns out to be formally isomorphic to the equilibrium analysis in the benchmark model. This property, which is not trivial, permits us to translate our earlier multipleequilibria result to a result of multiple steady states.

\subsection{The environment}

The economy is populated by a sequence of non-overlapping generations, indexed by $t \in\{. .,-1,0,1, \ldots\}$. Each generation lives for one period. Within each generation, there is a single effort choice, made after the tax is voted on. Parents enjoy utility for leaving a bequest to their children; by "bequests" we mean, not only monetary transfers, but also all other sorts of parental investment. ${ }^{25}$

Let $c_{t}^{i}$ denote the consumption of family $i$ in generation $t$, and $k_{t}^{i}$ the bequest the family leaves to the next generation. Individual preferences are given by

$$
\begin{gathered}
U_{t}^{i}=u_{t}^{i}-\gamma \Omega_{t} \\
u_{t}^{i}=V_{t}^{i}\left(c_{t}^{i}, k_{t}^{i}, e_{t}^{i}\right)=\frac{1}{(1-\alpha)^{1-\alpha} \alpha^{\alpha}}\left(c_{t}^{i}\right)^{1-\alpha}\left(k_{t}^{i}\right)^{\alpha}-\frac{1}{\beta_{t}^{i}}\left(e_{t}^{i}\right)^{2} .
\end{gathered}
$$

The first term in $u_{t}^{i}$ represents the utility from own consumption and bequests, whereas

\footnotetext{
${ }^{24}$ For a recent discussion of the intergenerational transfer of wealth and its effect on effort choices and entrepreneurship, see Caselli and Gennaioili (2003).

${ }^{25}$ This is of course a short cut, which is easier to model than adding the utility function of the children into that of the parents. It also rules out the dependence of political decisions in one generation on expectations about political decisions in future generations.
} 


\section{FAIRNESS AND REDISTRIBUtion}

the second term is the disutility of effort. For simplicity, we have assumed a CobbDouglas aggregator over consumption and bequests, with $\alpha \in(0,1)$ now corresponding to the fraction of wealth allocated to bequests. As in the benchmark model, the cost of effort is quadratic, and $\beta_{t}^{i}$ parametrizes "laziness". Finally, the constant $\frac{1}{(1-\alpha)^{1-\alpha} \alpha^{\alpha}}$ is an innocuous normalization.

The budget constraint for household $i$ is given by

$$
c_{t}^{i}+k_{t}^{i}=\left(1-\tau_{t}\right) y_{t}^{i}+G_{t}
$$

while the budget constraint for the government is $G_{t}=\tau_{t} \bar{y}_{t}$, where $\bar{y}_{t} \equiv \int_{i} y_{t}^{i}$ is mean income in generation $t$. Pre-tax wealth is now given by the sum of effort, luck, and parental investment:

$$
y_{t}^{i}=A_{t}^{i} e_{t}^{i}+\eta_{t}^{i}+k_{t-1}^{i}
$$

$A_{t}^{i}$ represents, as before, innate talent, which is independent of family history. To the extent that productivity reflects child-rearing, education, and other shorts of parental investment, we capture its effect on income through $k_{t-1}^{i}$, not $A_{t}^{i}{ }^{26}$ Finally, $\eta_{t}^{i}$ is again noise, which captures luck (or other unworthy income) within the life of the agent.

\subsection{Market outcomes and fairness}

Household $i$ in generation $t$ chooses consumption, bequest, and effort $\left(c_{t}^{i}, k_{t}^{i}, e_{t}^{i}\right)$ so as to maximize utility (16) subject to the budget constraint (18), taking political and social outcomes $\left(\tau_{t}, \Omega_{t}\right)$ as given. It follows that the optimal consumption and bequests are

$$
\begin{gathered}
c_{t}^{i}=(1-\alpha)\left[\left(1-\tau_{t}\right) y_{t}^{i}+\tau_{t} \bar{y}_{t}\right], \\
k_{t}^{i}=\alpha\left[\left(1-\tau_{t}\right) y_{t}^{i}+\tau_{t} \bar{y}_{t}\right],
\end{gathered}
$$

which give utility $u_{t}^{i}=V_{t}^{i}\left(c_{t}^{i}, k_{t}^{i}, e_{t}^{i}\right)=\left[\left(1-\tau_{t}\right) y_{t}^{i}+\tau_{t} \bar{y}_{t}\right]-e_{t}^{i} /\left(2 \beta_{t}^{i}\right)$. The optimal level of effort is thus

$$
e_{t}^{i}=\left(1-\tau_{t}\right) A_{t}^{i} \beta_{t}^{i}
$$

\footnotetext{
${ }^{26}$ Introducing a production complementarity between parental investment, $k_{t-1}^{i}$, and individual effort, $e_{t}^{i}$, would complicate the algebra, but would not alter our qualitative findings.
} 


\section{A. Alesina and G.M. Angeletos}

Since wealth in one generation depends on bequests and partent investment from the previous generation, which in turn depend on wealth in the previous generation, the wealth of any given individual depends on the contribution of talent and effort and the realization luck, not only during his own lifetime, but also along his whole family tree. We thus need to adjust our measures of fair outcomes for the propagation of luck through intergenerational transfers. Assuming that bequests and parental investments are considered fair only to the extent that they reflect effort and talent, not pure luck, we define fair outcomes as the luck-free counterparts of consumption, bequests, and wealth: $\widehat{c}_{t}^{i}=(1-\alpha) \widehat{y}_{t}^{i}, \widehat{k}_{t}^{i}=(1-\alpha) \widehat{y}_{t}^{i}$, and $\widehat{y}_{t}^{i}=A_{t}^{i} e_{t}^{i}+\widehat{k}_{t-1}^{i}$. Iterating the latter backwards, we infer that the fair level of wealth is given by the cumulative effect of talent and effort throughout the individual's family history:

$$
\widehat{y}_{t}^{i}=\sum_{s \leq t} \alpha^{s-t} A_{s}^{i} e_{s}^{i}
$$

Similarly, the residual between actual and fair wealth is the cumulative effect of luck:

$$
y_{t}^{i}-\widehat{y}_{t}^{i}=\sum_{s \leq t} \alpha^{s-t} \eta_{s}^{i} .
$$

Social injustice is again the distance between actual and fair utility in any given generation:

$$
\Omega_{t} \equiv \int\left[u_{t}^{i}-\widehat{u}_{t}^{i}\right]^{2}
$$

where $u_{t}^{i}=V_{t}^{i}\left(c_{t}^{i}, k_{t}^{i}, e_{t}^{i}\right)$ and $\widehat{u}_{t}^{i}=V_{t}^{i}\left(\widehat{c}_{t}^{i}, \widehat{k}_{t}^{i}, e_{t}^{i}\right)$. Note that $u_{t}^{i}-\widehat{u}_{t}^{i}=\left(1-\tau_{t}\right) y_{t}^{i}+\tau_{t} \bar{y}_{t}-\widehat{y}_{t}^{i}$ for all $i$, which implies that $\Omega_{t}$ measures the distance between actual disposable wealth and fair wealth, exactly like in the benchmark model. Indeed, assuming that $\delta_{t}^{i} \equiv \beta_{t}^{i}\left(A_{t}^{i}\right)^{2}$ and $\eta_{t}^{i}$ are uncorrelated with each other, which ensures that $\widehat{y}_{t}^{i}$ and $y_{t}^{i}-\widehat{y}_{t}^{i}$ are also uncorrelated, we obtain

$$
\Omega_{t}=\tau_{t} \operatorname{Var}\left(\widehat{y}_{t}^{i}\right)+\left(1-\tau_{t}\right) \operatorname{Var}\left(y_{t}^{i}-\widehat{y}_{t}^{i}\right) .
$$

Once again, this implies that the optimal tax rate is bound to decrease with the signalto-noise ratio in the wealth distribution

On the other hand, the equilibrium signal-to-noise ratio now reflects the whole history of the economy. From (22) and (23), $\widehat{y}_{t}^{i}=\sum_{s \leq t} \alpha^{s-t}\left(1-\tau_{s}\right) \delta_{s}^{i}$, which together with (24) 


\section{FAIRNESS AND REDistribution}

implies that

$$
\frac{\operatorname{Var}\left(\widehat{y}_{t}^{i}\right)}{\operatorname{Var}\left(y_{t}^{i}-\widehat{y}_{t}^{i}\right)}=\frac{\operatorname{Var}\left(\sum_{s \leq t} \alpha^{s-t}\left(1-\tau_{s}\right) \delta_{s}^{i}\right)}{\operatorname{Var}\left(\sum_{s \leq t} \alpha^{s-t} \eta_{s}^{i}\right)} .
$$

The signal-to-noise ratio is thus decreasing in $\tau_{s}$ for every $s \leq t$. That is, how fair the wealth distribution is in generation $t$ depends, not only on the policies chosen by the same generation, but also on the policies chosen by all past generations $s \leq t-1$. A society that had a history of high distortions will tend to have inherited a rather unfair wealth distribution, which makes it more likely that it favors aggressive redistribution in the present. As a result, unfair outcomes and high distortions can be self-propagating across generations, opening the door to multiple steady states.

\subsection{Multiple steady states}

We look for fixed points such that, if $\tau_{s}=\tau$ for all generations $s \leq t-1$, then $\tau_{t}=\tau$ is optimal for generation $t$. To simplify, we assume that $\delta_{t}^{i} \equiv \beta_{t}^{i}\left(A_{t}^{i}\right)^{2}$ and $\eta_{t}^{i}$ are i.i.d. across $i$ but fully persistent across $t,{ }^{27}$ with $\operatorname{Var}\left(\delta_{t}^{i}\right)=\sigma_{\delta}^{2}$ and $\operatorname{Var}\left(\eta_{t}^{i}\right)=\sigma_{\eta}^{2}$. Let $\tau_{s}=\tau_{e}$ for all $s \leq t-1$. The signal-to-noise ratio and the social injustice in generation $t$ reduce to

$$
\begin{gathered}
\frac{\operatorname{Var}\left(\widehat{y}_{t}^{i}\right)}{\operatorname{Var}\left(y_{t}^{i}-\widehat{y}_{t}^{i}\right)}=\left[1-\alpha \tau_{e}-(1-\alpha) \tau_{t}\right]^{2} \frac{\sigma_{\delta}^{2}}{\sigma_{\eta}^{2}}, \\
\Omega_{t}=\tau_{t}^{2}\left[1-\alpha \tau_{e}-(1-\alpha) \tau_{t}\right]^{2} \sigma_{\delta}^{2}+\left(1-\tau_{t}\right)^{2} \sigma_{\eta}^{2},
\end{gathered}
$$

which are formally identical to conditions (12) and (14) in the benchmark model. The only difference is that $\tau_{e}$ now represents the history of past policies rather than the anticipated same-period policy. Letting $\Delta=\bar{\delta}-\delta_{m}$ and normalizing $\delta_{m}=2(1-\alpha)$, the utility of the median voter in generation $t$ is given by

$$
U_{t}^{m}=\left(1-\alpha \tau_{e}^{2}\right)-(1-\alpha) \tau_{t}^{2}+\left[1-\alpha \tau_{e}-(1-\alpha) \tau_{t}\right] \tau_{t} \Delta-\gamma \Omega_{t}
$$

which is again formally identical to condition (13) in the benchmark model. We conclude

\footnotetext{
${ }^{27}$ The multiplicity result extends to any serial correlation in $\delta_{t}^{i}$ or $\eta_{t}^{i}$.
} 


\section{A. Alesina and G.M. Angeletos}

Proposition 3 When all generations before $t$ have chosen $\tau_{e}$, the optimal tax for generation $t$ is $\tau_{t}=f\left(\tau_{e} ; \mathcal{E}\right)$, where

$$
\begin{aligned}
f\left(\tau_{e} ; \mathcal{E}\right) \equiv \arg \min _{\tau \in[0,1]}\{ & (1-\alpha) \tau^{2}+\left(1-\alpha \tau_{e}-(1-\alpha) \tau\right)^{2} \gamma \sigma_{\delta}^{2} \\
& \left.+(1-\tau)^{2} \gamma \sigma_{\eta}^{2}-\tau\left[1-\alpha \tau_{e}-(1-\alpha) \tau\right] \Delta\right\} .
\end{aligned}
$$

Comparing the above with Proposition 1, we see that the functional form of $f$ is identical to that in the benchmark model. The only difference is that $f$ now represents the best reaction of a given generation against a stationary history of past policies, rather than the best reaction against same-period market expectations. Hence, the fixed points of $f$ now represent the steady states of the economy.

Proposition 4 A steady state always exists and corresponds to any fixed point of $f$, where $f$ is given by (31). If $\gamma=0$, there is a unique steady state. If instead $\gamma>0$, there genericly exist multiple steady states. The steady state with the lower tax is the one with the highest inequality but also the highest signal-to-noise ratio.

The example of Figure 2 can thus be directly reinterpreted in the present context, provided we read $\tau$ as the policy in some given generation and $\tau_{e}$ as the history of policies in all previous generations. Multiple steady states exist when the social desire for fairness is sufficiently high and the relative effect of luck is moderate. The two extreme intersection points give the two stable steady states. $U S$ is characterized by persistently lower taxation, lower distortions, and fairer outcomes as compared to $E U$, but $E U$ might be preferred behind the veil of ignorance.

We conclude that different historical experiences may have lead Americans and Europeans to different steady states, in which different social beliefs and political outcomes are self-reproducing. Also, these results suggest that reforms of the welfare and regulatory state, no matter which direction they favor, may need to be large and persistent to be politically sustainable. In practice, this means that governments need to persuade that, although such reforms may generate rather unfair outcomes in the short run, they will not be reverted in the near feature and they will ultimately ensure fairer outcomes for future generations. 


\section{FAIRNESS AND REDISTRIBUTION}

Remark. In writing (23), we assumed that the society wishes to correct the cumulative effect of pure luck, but otherwise parents are fully entitled to make different transfers to their children deriving from different levels of effort. However, the society may not want to keep children born by unworthy parents responsible for their parents' laziness and lack of care. There is then a conflict between what is considered fair vis-a-vis parents and what is considered fair vis-a-vis children. As a result, the society may like to make parents only partly entitled to leaving different bequests to their children, even if these differences reflect different levels of effort or parental care, so as to further equalize opportunities across children. In the Appendix, we consider a simple extension in which children are entitled only to a fraction $\lambda$ of fair bequests. The positive feedback from past to current policies remains for any $\lambda>0$ and the multiplicity survives for $\lambda$ sufficiently high.

\section{Conclusion}

Although we focused on income taxation and redistribution, the demand for fairness may have similar implications for many other policy choices, such as the regulation of product and labor markets. Our analysis thus sheds some light on why differences in attitudes towards the market mechanism are so rooted in American and European cultures. In Europe, opportunities for wealth and success have been severely restrained by class differences at least since medieval times. ${ }^{28}$ At the time of the extension of the franchise, the distribution of income was perceived as unfair because it was generated more by birth and nobility than by ability and effort. The "invisible hand" has frequently favored the lucky and privileged rather than the talented and hard-working. Europeans have thus favored aggressive redistributive polices and other forms of government intervention. In the "land of opportunities," the perception was instead that those who were wealthy and successful had "made it" on their own. Americans have thus chosen strong property protection, limited regulation, and low redistribution, which in turn have resulted to fewer distortions, more efficient market outcomes, and a smaller effect of "luck". Today, the

\footnotetext{
${ }^{28}$ Marx and Engels had already identified in the lack of a feudal period as one of the reasons why in the United States it would have been much harder to create a Communist party committed to wealth expropriation. See Alesina and Glaeser (2004) for more discussion.
} 


\section{A. Alesina and G.M. Angeletos}

"self-made man" remains very much an American "icon"; and Americans remain more averse to government intervention than Europeans.

In this paper, the definition of fairness was embedded in individual preferences. One may think of such preferences for fairness as a metaphor for a social norm that supports a socially preferable outcome. ${ }^{29}$ Alternatively, one can interpret "luck" as the effect of corruption, rent seeking, political subversion, theft, fraud, and the like - activities that involve private but no social benefits, and may thus be naturally treated by society as "unjust". ${ }^{30}$ Finally, Amador, Angeletos and Werning (2003) consider an extension of the Mirrlees paradigm with two types of privately-observed idiosyncratic shocks, one which is desirable to insure (taste shocks) and another which is undesirable to insure (self-control shocks). Although their environment is very different from ours, one of their results is reassuringly similar: The optimal level of redistribution tends to decrease with the ratio of the variance of self-control shocks to the variance of taste shocks, which could be interpreted as the ratio of fair to unfair inequality. It remains an open question why societies consider some sources of income as "fair" and others as "unfair".

\section{Appendix}

Proof of Proposition 1. Conditions (2), (10), and (11) imply that, in equilibrium, the level of consumption and the cost of investment and effort for agent $i$ are

$$
\begin{gathered}
c_{i}=(1-\tau) y_{i}+\tau \bar{y}=\left[1-\alpha \tau_{e}-(1-\alpha) \tau\right]\left[\delta_{i}+\tau\left(\bar{\delta}-\delta_{i}\right)\right]+\left[\eta_{i}+\tau\left(\bar{\eta}-\eta_{i}\right)\right], \\
\frac{1}{2 \beta_{i}}\left[\alpha k_{i}^{2}+(1-\alpha) e_{i}^{2}\right]=\frac{1}{2}\left[\alpha\left(1-\tau_{e}\right)^{2}+(1-\alpha)(1-\tau)^{2}\right] \delta_{i}
\end{gathered}
$$

\footnotetext{
${ }^{29}$ See Cole, Mailath and Postlewaite (1992) for how different social norms may result in different reduced-form preferences.

${ }^{30}$ For example, Murphy, Shleifer and Vishny $(1991,1993)$ and Angeletos and Kollintzas (1997) discuss how corruption and rent seeking can be detrimental for economic growth. See the working-paper version of this article for a variant of our model where "luck" is replaced by a rent-seeking activity.
} 


\section{FAIRness AND Redistribution}

Combining, we infer that the equilibrium utility of agent $i$ is

$$
U_{i}=\left[1-\alpha \tau_{e}^{2}-(1-\alpha) \tau^{2}\right] \frac{\delta_{i}}{2}+\left[1-\alpha \tau_{e}-(1-\alpha) \tau\right] \tau\left(\bar{\delta}-\delta_{i}\right)+\left[\eta_{i}+\tau\left(\bar{\eta}-\eta_{i}\right)\right]-\gamma \Omega
$$

with $\Omega$ as in (14). It follows that

$$
\frac{\partial^{2} U_{i}}{\partial \tau^{2}}=-(1-\alpha)\left(2 \bar{\delta}-\delta_{i}\right)-2 \gamma\left\{\sigma_{\delta}^{2}\left[1-2 \tau(1-\alpha)-\alpha \tau_{e}\right]^{2}+\sigma_{\eta}^{2}\right\}
$$

and therefore $2 \bar{\delta}>\max \left\{\delta_{i}\right\}$ suffices for preferences to be single-picked in $\tau$ for all agents, in which case the median voter theorem applies. In any event, we assume that the policy maximizes the utility of the median voter. Evaluating (32) for $i=m$, using $\eta_{m}=0$, $\Delta=\bar{\delta}-\delta_{m}$, and the normalization $\delta_{m}=2$, gives (13).

Next, define $W\left(\tau, \tau_{e}\right)=\left(1-\alpha \tau_{e}^{2}\right)-U_{m}$, or equivalently

$W\left(\tau, \tau_{e}\right)=(1-\alpha) \tau^{2}+\tau^{2}\left[1-\alpha \tau_{e}-(1-\alpha) \tau\right]^{2} \gamma \sigma_{\delta}^{2}+(1-\tau)^{2} \gamma \sigma_{\eta}^{2}-\tau\left[1-\alpha \tau_{e}-(1-\alpha) \tau\right] \Delta$

and $f o c\left(\tau, \tau_{e}\right)=\frac{\partial W}{\partial \tau}$. Letting $f\left(\tau_{e}\right)=\arg \min _{\tau \in[0,1]} W\left(\tau, \tau_{e}\right)$ gives $(15)$. Note that $W$ is strictly convex, since $\frac{\partial f o c}{\partial \tau}=\frac{\partial^{2} W}{\partial \tau^{2}}=2(1-\alpha)(1+\Delta)+2 \gamma\left\{\sigma_{\delta}^{2}\left[1-2 \tau(1-\alpha)-\alpha \tau_{e}\right]^{2}+\sigma_{\eta}^{2}\right\}>$ 0 . By implication, the first-order condition is both necessary and sufficient, in which case $\tau=f\left(\tau_{e}\right)$ is the unique solution to $f o c\left(\tau, \tau_{e}\right)=0$. Note that $f o c\left(\tau, \tau_{e}\right)$ is a third-order polynomial - unless $\gamma=0$, in which case it reduces to a linear relation).

Of course, if $\gamma=\Delta=0$, it is immediate that $f\left(\tau_{e}\right)=0$ for all $\tau_{e} \in[0,1]$. If instead $\gamma>0$ and/or $\Delta>0$, it is easy to check that $\left.f o c\right|_{\tau=0}=-2 \gamma \sigma_{\eta}^{2}-\Delta\left(1-\alpha \tau_{e}\right)<0$, which ensures $f\left(\tau_{e}\right)>0$ for all $\tau_{e} \in[0,1]$. If $\Delta>0$ but $\gamma=0$, the first-order condition gives $f\left(\tau_{e}\right)=\frac{\Delta\left(1-\alpha \tau_{e}\right)}{2(1+\Delta)}$ and therefore $\frac{\partial f}{\partial \tau^{e}}<0, \frac{\partial f}{\partial \Delta}>0$, and $\frac{\partial f o c}{\partial \sigma_{\delta}}=\frac{\partial f o c}{\partial \sigma_{\eta}}=0$.

If instead $\gamma>0$, the first-order condition is a third-order polynomial in $\tau$. Closedform solution is thus possible in principle, but it turns out to be so complicated that it is useless for comparative statics. We thus opt to analyze the solution implicitly. It is easy to check that $\frac{\partial f o c}{\partial \sigma_{\eta}}=-2(1-\tau), \frac{\partial f o c}{\partial \sigma_{\delta}}=2 \gamma \sigma_{\delta}^{2}\left[1-\alpha \tau_{e}-(1-\alpha) \tau\right]\left[1-\alpha \tau_{e}-2(1-\alpha) \tau\right]$, and $\frac{\partial f o c}{\partial \Delta}=-\left[1-\alpha \tau_{e}-2(1-\alpha) \tau\right]$. By the Implicit Function Theorem, it follows that $\frac{\partial f o c}{\partial \sigma_{\eta}}>0$ necessarily. On the other hand, $\frac{\partial f}{\partial \sigma_{\delta}}<0 \Leftrightarrow \frac{\partial f}{\partial \Delta}>0 \Leftrightarrow \tau<\frac{1-\alpha \tau_{e}}{2(1-\alpha)}$. Let $h\left(\tau_{e}\right) \equiv f o c\left(\frac{1-\alpha \tau_{e}}{2(1-\alpha)}, \tau_{e}\right)=\frac{1}{1-\alpha}\left\{\left[1-\alpha-(1-2 \alpha) \gamma \sigma_{\eta}^{2}\right]-\alpha\left[1-\alpha+\gamma \sigma_{\eta}^{2}\right] \tau_{e}\right\}$ and note that $\tau<\frac{1-\alpha \tau_{e}}{2(1-\alpha)}$ if and only if $h\left(\tau_{e}\right)>0$. Since $h^{\prime}(\tau e)<0$, there exist a unique $\widehat{\tau}_{e}$ such that 


\section{A. Alesina and G.M. Angeletos}

$h\left(\tau_{e}\right)>0$ if and only if $\tau_{e}<\widehat{\tau}_{e}$; this threshold is $\widehat{\tau}_{e}=\frac{1-\alpha-(1-2 \alpha) \gamma \sigma_{\eta}^{2}}{\alpha\left(1-\alpha+\gamma \sigma_{\eta}^{2}\right)}$. For $\gamma \sigma_{\eta}^{2}$ sufficiently small, $\widehat{\tau}_{e}>1$, in which case $\tau_{e}<\widehat{\tau}_{e}$ is trivially satisfied for all $\tau_{e} \in[0,1]$. We conclude that $\frac{\partial f}{\partial \sigma_{\delta}}<0$ and $\frac{\partial f}{\partial \Delta}>0$, unless both $\gamma \sigma_{\eta}^{2}$ and $\tau_{e}$ are sufficiently high. Next, note that $\alpha=0$ implies $\frac{\partial W}{\partial \tau_{e}}=0$ and thus $\frac{\partial f}{\partial \tau_{e}}=0$. Therefore, $\alpha$ sufficiently large is necessary for the possibility that $f$ is increasing in $\tau$. Finally, $\left.\frac{\partial f o c}{\partial \tau^{e}}\right|_{\tau^{e}=0}=-\gamma \alpha \sigma_{\delta}^{2} \tau\{[2-3(1-\alpha) \tau]-\Delta / \gamma\}$. It follows that $\alpha>1 / 3$ and $\gamma>\Delta /[2-3(1-\alpha)]$ suffice for $\left.\frac{\partial f o c}{\partial \tau^{e}}\right|_{\tau^{e}=0}<0$, in which case $\left.\frac{\partial f}{\partial \tau^{e}}\right|_{\tau^{e}=0}>0$; that is, $f$ is initially increasing in $\tau_{e}$.

Proof of Proposition 2. That $f$ has at least one fixed point follows immediately from the fact that $f$ is bounded and continuous. First, note that $\tau=\tau_{e}=1$ implies $\frac{\partial W}{\partial \tau}=(1-\alpha)(2+\Delta)$ and thus, for any $\Delta \geq 0, f(1)<1$ if and only if $\alpha<1$. Therefore, $\alpha<1$ is necessary and sufficient for $\tau=1$ not to be a fixed point. Next, note that Proposition 1 established that $f$ is non-increasing in $\tau$ for either $\gamma=0$ or $\alpha=0$. It follows that $f$ has a unique fixed point whenever $\gamma=0$ or $\alpha=0$, and by continuity also when $\gamma$ or $\alpha$ are sufficiently close to zero. For $\gamma$ and $\alpha$ sufficiently high, on the other hand, $f$ is increasing over some portions, which opens the door to multiple fixed points. The example in the main text is a generic example in which $f$ has multiple fixed points. Simulations suggest that multiple equilibria tend to exist for intermediate values of $\sigma_{\delta} / \sigma_{\eta}$. The comparative statics of the equilibria with respect to $\sigma_{\delta}$ and $\sigma_{\eta}$ follow directly from the comparative statics of $f$ (see Proposition 2 again). Finally, in equilibrium, $\operatorname{Var}\left(y_{i}\right)=(1-\tau)^{2} \sigma_{\delta}^{2}+\sigma_{\eta}^{2}$ and $\operatorname{Var}\left(\widehat{y}_{i}\right) / \operatorname{Var}\left(y_{i}-\widehat{y}_{i}\right)=(1-\tau)^{2} \sigma_{\delta}^{2} / \sigma_{\eta}^{2}$, which are both decreasing in $\tau$.

Proof of Proposition 3 and 4. In the main text we showed that the preferences over $\tau_{t}$ in the dynamic model coincide with the preferences over $\tau$ in the benchmark model. The results then follow by implication of Propositions 1 and 2 .

Equalizing opportunities for children. Let $\lambda \in(0,1)$ be the fraction of fair parental bequests that children are entitled to. That is, the children's fair level of wealth is now given by

$$
\widehat{y}_{t}^{i} \equiv A_{t}^{i} e_{t}^{i}+\lambda \sum_{s \leq t-1} \alpha^{s-t} A_{s}^{i} e_{s}^{i}
$$




\section{FAIRNESS AND REDistribUtion}

$1-\lambda$ can be interpreted as a measure of the social desire for equalizing opportunities across children. If $\tau_{s}=\tau_{e}$ for all $s \leq t-1$, the above reduces in equilibrium to

$$
\widehat{y}_{t}^{i} \equiv\left(1-\tau_{t}\right) \delta_{t}^{i}+(1-\alpha \lambda) \sum_{s \leq t-1} \alpha^{s-t} A_{s}^{i} e_{s}^{i}
$$

The steady-state analysis goes through as before, simply replacing $\alpha$ with $\alpha \lambda$. Normalizing $\delta_{m}=2(1-\alpha \lambda) /(1-\alpha)$, and letting $\Delta=0$ for simplicity, we conclude that the optimal tax rate in generation $t$ when past generations have chosen $\tau_{e}$ is given by $\tau_{t}=f\left(\tau_{e}\right)$, where

$$
f\left(\tau_{e}\right) \equiv \arg \min _{\tau}\left\{\tau^{2}(1-\alpha \lambda)+\tau^{2}\left(1-\alpha \lambda \tau_{e}-(1-\alpha \lambda) \tau\right)^{2}\left(\gamma \sigma_{\delta}^{2}\right)+(1-\tau)^{2}\left(\gamma \sigma_{\eta}^{2}\right)\right\}
$$

This economy is thus isomorphic to the benchmark economy provided we replace $\alpha$ with $\alpha \lambda$. It follows that the possibility of multiple steady states remains as long as $\lambda$ is not very small. Moreover, the tax rate in any (stable) steady state is decreasing in $\lambda$; that is, redistribution increases with a higher desire to equalize opportunities across children.

Remark. We have considered only one kind of taxation and redistribution, namely income taxation coupled with lump sum transfers. Different redistributive goals given a desire for fairness could be achieved by using a mixture of different tax and redistribution instruments. For example, we can introduce an inheritance tax in addition to the income tax. A society may then consider an inheritance more or less "fair" depending on whether higher bequests are or are not due to higher ability and effort by the previous generation. Similarly, one could consider public provision of education. Our model would predict that, in an attempt to correct for the more unfair variation in children's opportunities, Europe adopts a larger government intervention in education. 
A. Alesina and G.M. Angeletos

\section{References}

[1] Acemoglu, D. (1998), "Why Do New Technologies Complement Skills? Direct Technical Change and Wage Inequality," Quarterly Journal of Economics 113, 1055-89.

[2] Acemoglu, D. (2003), "Cross Country Inequality Trends," Economic Journal 113, $121-49$.

[3] Alesina, A., R. Baqir, and W. Easterly (1999), "Public Goods and Ethnic Divisions" Quarterly Journal of Economics 114, 1243-84.

[4] Alesina, A., A. Devleeschauer, W. Easterly, W. Kurlat and R. Wacziarg (2003), "Fractionalization," Journal of Economic Growth 8, 155-194.

[5] Alesina, A., E. Glaeser, and B. Sacerdote (2001), "Why Doesn't the United States Have a European-style Welfare State?" Brookings Papers on Economic Activity $2: 2001$.

[6] Alesina A., and E. Glaeser (2004), Fighting Poverty in the US and Europe: A World of Difference, Oxford University Press, forthcoming.

[7] Alesina, A., and E. La Ferrara (2003), "Preferences for Redistribution in the Land of Opportunities" unpublished.

[8] Amador, M., Angeletos, G.M., and I. Werning (2003), "Mirrlees Meets Pigou," work in progress.

[9] Angeletos, G.M., and T. Kollintzas (1997), "Rent Seeking, Corruption and Growth: A Simple Model," CEPR Discussion Paper 2464.

[10] Ball, S., C. Eckel, P. Grossman, and W. Zane (1996), "Status in Markets," unpublished.

[11] Banerjee, A. (1997), "A Theory of Misgovernance," Quarterly Journal of Economics $112,1289-1331$. 


\section{FAIRNESS AND REDistribUtion}

[12] Benabou, R. (2000), "Unequal Societies: Income Distribution and the Social Contract," American Economic Review 90, 96-129.

[13] Benabou, R., and E. Ok (2001), "Social Mobility and the Demand for Redistribution: The POUM Hypothesis," Quarterly Journal of Economics 116, 447-87.

[14] Benabou, R., and J. Tirole (2003), "Belief in a Just World and Redistributive Policies," unpublished.

[15] Caselli, F., and N. Gennaioli (2003), "Dynastic Management," unpublished.

[16] Checchi, D., A. Ichino and A. Rustichini (1999), "More Equal and Less Mobile? Education Financing and Intergenerational Mobility in Italy and in the US" Journal of Public Economics 74, 351-93.

[17] Clark, J. (1998), "Fairness in Public Good Provision: An Investigation of Preferences for Equality and Proportionality," Canadian Journal of Economics 31, 708-729.

[18] Cole, H., G. Mailath, and A. Postlewaite (1992), "Social Norms, Savings Behavior, and Growth," Journal of Political Economy 100, 1092-1125.

[19] Corneo, G., and H.P. Gruner (2002), "Individual Preferences for Political Redistribution," Journal of Public Economics 83, 83-107.

[20] Deininger, K., and L. Squire (1996), "A New Data Set Measuring Income Inequality," World Bank Economic Review 10, 565-91.

[21] Fehr, E., and K. Schmidt (2001), "Theories of Fairness and Reciprocity - Evidence and Economic Applications," prepared for the 8th World Congress of the Econometric Society.

[22] Fields, G., and E. Ok (1999), "Measuring Movements of Income," Econometrica 66, $455-71$.

[23] Fong, C. (2002), "Social Preferences, Self-Interest and the Demand for Redistribution," Journal of Public Economics 82, 225-46. 


\section{A. Alesina and G.M. Angeletos}

[24] Glaeser, E. (2002), "A Model of Hatred," unpublished.

[25] Gottschalk, P., and E. Spolaore (2002), "On the Evaluation of Economic Mobility," Review of Economic Studies, forthcoming.

[26] Hoffman, E., K. McCabe, K. Shachat, and V. Smith (1996), "On Expectations and the Monetary Stakes in Ultimatum Games," International Journal of Game Theory 25, 289-301.

[27] Hoffman, E., and M. Spitzer (1985), "Entitlements, Rights, and Fairness: An Experimental Investigation of Subject's Concepts of Distributive Justice," Journal of Legal Studies 14, 259-97.

[28] Lindbeck, A., S. Nyberg and J. Weibull (1998), "Social Norms and Economic Incesntives in the Welfare State," Quarterly Journal of Economics 114, 1-35.

[29] Lindbeck, A., P. Molander, T. Persson, O. Petterson, B. Swedenberg, and N. Thygesen (1994), The Swedish experiment, Cambridge, Mass: MIT Press.

[30] La Porta, R. F. Lopez de Silanes, A. Shleifer, and R. Vishny (1999), "The Quality of Government" Journal of Law, Economics and Organization.

[31] Meltzer, A., and S. Richard (1981), "A Rational Theory of the Size of Government," Journal of Political Economy 89, 914-27.

[32] Murphy, K., A. Shleifer, and R. Vishny (1991), "The Allocation of Talent: Implications for Growth," Quarterly Journal of Economics 106, 503-30.

[33] Murphy, K., A Shleifer, and R. Vishny (1993), "Why is Rent-Seeking so Costly to Growth?" American Economic Review Papers and Proceedings 83, 409-14.

[34] Nickell, S. (1997), "Unemployment and Labor Market Rigidities:Europe versus North America," Journal of Economic Perspectives 11, 55-74.

[35] Nickell, S., and R. Layard (1999), "Labor Market Institutions and Economic Performance," in O. Ashenfelter and D. Card (eds) Handbook of Labor Economics, North Holland Amsterdam. 


\section{FAIRNESS AND REDISTRIBUtion}

[36] Perotti, R. (1996), "Growth, Income Distribution and Democracy: What the Data Say," Journal of Economic Growth 1, 149-87.

[37] Piketty, T. (1995), "Social Mobility and Redistributive Politics," Quarterly Journal of Economics 110, 551-84.

[38] Prescott E. (2003) "Why do Americans work so much more than Europeans?" Federal Reserve of Minneapolis, Working Paper n. 321

[39] Rawls, J. (1971), The Theory of Justice, Harvard University Press.

[40] Romer, T. (1975), "Individual Welfare, Majority Voting and the Properties of a Linear Income Tax," Journal of Public Economics 7, 163-88.

[41] Shleifer, A. and R. Vishny (1993), "Corruption," Quarterly Journal of Economics 104, 599-617.

[42] Tirole, J. (1993), "A Theory of Collective Reputations (with Applications to the Persistence of Corruption and to Firm Quality)," Review of Economic Studies 63, $1-22$. 


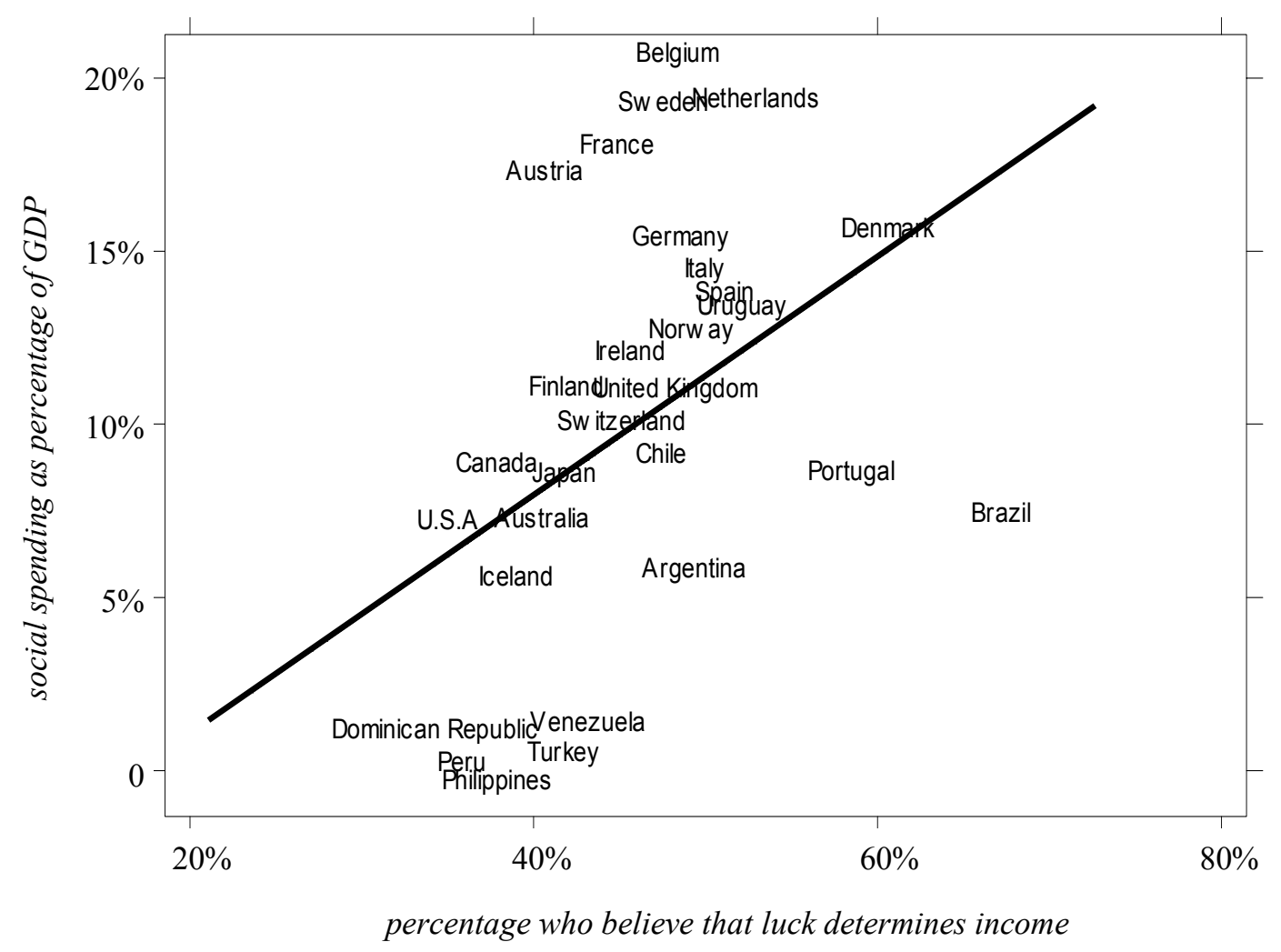

\section{Figure 1}

Reproduced from Alesina, Gleaser and Sacerdote (2001). This scatterplot illustrates the positive cross-country correlation between the percentage of GDP allocated to social spending and the fraction of respondents to the World Value Survey who believe that luck determines income. 


\section{Table 1}

Effect of belief that luck determines income on aggregate social spending (cross-country data)

\begin{tabular}{|c|c|c|c|c|}
\hline \multicolumn{5}{|c|}{ Dependent variable: Social spending as percent of GDP } \\
\hline & 1 & 2 & 3 & 4 \\
\hline $\begin{array}{l}\text { Mean belief that luck } \\
\text { determines income }\end{array}$ & $\begin{array}{l}\mathbf{3 2 . 7 2 8}^{* * *} \\
(2.925)\end{array}$ & $\begin{array}{l}32.272^{* * *} \\
(3.064)\end{array}$ & $\begin{array}{l}\text { 36.430 } \\
(3.305)\end{array}$ & $\begin{array}{l}\mathbf{3 1 . 7 8 2}^{* *} \\
(2.521)\end{array}$ \\
\hline Gini coefficient & & $\begin{array}{l}-0.306^{*} \\
(1.724)\end{array}$ & $\begin{array}{l}-0.238^{*} \\
(1.739)\end{array}$ & $\begin{array}{l}-0.115 \\
(0.613)\end{array}$ \\
\hline GDP per capita & & & $\begin{array}{c}3.148 \\
(1.348)\end{array}$ & $\begin{array}{c}4.754 \\
(1.548)\end{array}$ \\
\hline Majoritarian & & & $\begin{array}{c}0.493 \\
(0.184)\end{array}$ & $\begin{array}{c}0.031 \\
(0.011)\end{array}$ \\
\hline Presidential & & & & $\begin{array}{c}-4.24 \\
(1.392)\end{array}$ \\
\hline Latin America & $\begin{array}{l}-6.950^{* * *} \\
(3.887)\end{array}$ & $\begin{array}{l}-4.323 \\
(1.472)\end{array}$ & $\begin{array}{l}-2.992 \\
(0.941)\end{array}$ & $\begin{array}{c}0.413 \\
(0.098)\end{array}$ \\
\hline Asia & $\begin{array}{l}-9.244^{* * *} \\
(6.684)\end{array}$ & $\begin{array}{l}-6.075^{* *} \\
(2.153)\end{array}$ & $\begin{array}{l}-0.808 \\
(0.142)\end{array}$ & $\begin{array}{c}4.657 \\
(0.618)\end{array}$ \\
\hline Constant & $\begin{array}{l}-3.088 \\
(0.590)\end{array}$ & $\begin{array}{c}7.907 \\
(1.396)\end{array}$ & $\begin{array}{l}-25.207 \\
(1.152)\end{array}$ & $\begin{array}{l}-41.401 \\
(1.425)\end{array}$ \\
\hline Observations & 29 & 26 & 26 & 26 \\
\hline Adjusted R-squared & 0.431 & 0.494 & 0.495 & 0.496 \\
\hline
\end{tabular}

Source: Total social spending is social spending as a percentage of GDP, from Persson and Tebellini (2000); original source: IMF. Majoritarian, presidential, and age structure are from Persson and Tabellini (2002). Ethnic fractionalization is from Alesina et al (2002). Mean belief that luck determines income is constructed using World Value Survey data for 1981-97 from the Institute for Social Research, University of Michigan. This variable corresponds to the response to the following question: "In the long run, hard work usually brings a better life. Or, hard work does not generally bring success; it's more a matter of luck and connections." The answers are coded 1 to 10 . We recoded on a scale 0 to 1 , with 1 indicating the strongest belief in luck.

Robust $t$ statistics in parentheses. * significant at 10\%; ** significant at 5\%; *** significant at $1 \%$. 
Table 2

The effect of belief that luck determines income on individual political orientation (individual data)

\begin{tabular}{|c|c|c|c|}
\hline \multicolumn{4}{|c|}{ Dependent variable: Being left on the political spectrum } \\
\hline & 1 & 2 & 3 \\
\hline $\begin{array}{l}\text { Individual belief that luck } \\
\text { determines income }\end{array}$ & & $\begin{array}{c}\mathbf{0 . 5 4 1}^{* * *} \\
(3.69)\end{array}$ & $\begin{array}{c}\mathbf{0 . 6 0 7}^{* * *} \\
(3.78)\end{array}$ \\
\hline Income & $\begin{array}{l}-0.01^{* * *} \\
(7.20)\end{array}$ & $\begin{array}{c}-0.009^{* * *} \\
(3.31)\end{array}$ & $\begin{array}{c}-0.009^{* * *} \\
(3.88)\end{array}$ \\
\hline Years of education & $\begin{array}{c}-0.004^{* * *} \\
(3.79)\end{array}$ & $\begin{array}{l}-0.002 \\
(0.74)\end{array}$ & $\begin{array}{l}0.000 \\
(0.07)\end{array}$ \\
\hline City population & $\begin{array}{l}0.01^{* * *} \\
(7.43)\end{array}$ & $\begin{array}{l}0.01^{* * *} \\
(4.29)\end{array}$ & $\begin{array}{c}0.009^{* * *} \\
(4.40)\end{array}$ \\
\hline White & $\begin{array}{l}0.036 \\
(4.83)\end{array}$ & $\begin{array}{l}0.051^{* * *} \\
(3.13)\end{array}$ & $\begin{array}{l}0.033^{* *} \\
(2.11)\end{array}$ \\
\hline Married & $\begin{array}{c}-0.026^{* * *} \\
(3.22)\end{array}$ & $\begin{array}{l}-0.03^{* * *} \\
(2.97)\end{array}$ & $\begin{array}{c}-0.032^{* * *} \\
(3.11)\end{array}$ \\
\hline No. of children & $\begin{array}{c}-0.009^{* * *} \\
(3.63)\end{array}$ & $\begin{array}{c}-0.01^{* * *} \\
(3.09)\end{array}$ & $\begin{array}{c}-0.013^{* * *} \\
(3.59)\end{array}$ \\
\hline Female & $\begin{array}{c}-0.044^{* * *} \\
(6.93)\end{array}$ & $\begin{array}{c}-0.043^{* * *} \\
(3.43)\end{array}$ & $\begin{array}{c}-0.039^{* * *} \\
(3.39)\end{array}$ \\
\hline US resident & $\begin{array}{c}-0.125^{* * *} \\
(12.14)\end{array}$ & $\begin{array}{c}-0.096^{* * *} \\
(3.31)\end{array}$ & $\begin{array}{l}-0.051 \\
(1.37)\end{array}$ \\
\hline Age group 18-24 & $\begin{array}{l}0.11^{* * *} \\
(6.19)\end{array}$ & $\begin{array}{l}0.078^{* * *} \\
(3.41)\end{array}$ & $\begin{array}{c}0.007^{* * *} \\
(3.11)\end{array}$ \\
\hline Age group 25-34 & $\begin{array}{l}0.131^{* * *} \\
(11.73)\end{array}$ & $\begin{array}{l}0.116^{* * *} \\
(7.23)\end{array}$ & $\begin{array}{l}0.114^{* * *} \\
(7.00)\end{array}$ \\
\hline Age group 35-44 & $\begin{array}{l}0.126^{* * *} \\
(12.03)\end{array}$ & $\begin{array}{l}0.117^{* * *} \\
(8.96)\end{array}$ & $\begin{array}{l}0.12^{* * *} \\
(9.27)\end{array}$ \\
\hline Age group $45-54$ & $\begin{array}{l}0.085^{* * *} \\
(7.98)\end{array}$ & $\begin{array}{l}0.081^{* * *} \\
(6.37)\end{array}$ & $\begin{array}{l}0.08^{* * *} \\
(6.03)\end{array}$ \\
\hline Age group 55-64 & $\begin{array}{l}0.039^{* * *} \\
(3.55)\end{array}$ & $\begin{array}{l}0.038^{* * *} \\
(3.25)\end{array}$ & $\begin{array}{c}0.037^{* * *} \\
(3.00)\end{array}$ \\
\hline Constant & $\begin{array}{l}0.347^{* * *} \\
(16.15)\end{array}$ & $\begin{array}{l}0.045 \\
(0.62)\end{array}$ & $\begin{array}{l}0.218 \\
(1.64)\end{array}$ \\
\hline Observations & 20269 & 16478 & 14998 \\
\hline R-squared & 0.03 & 0.03 & 0.04 \\
\hline
\end{tabular}

Source: The dependent variable is constructed using data from the World Value Survey. It is a 0 to 1 indicator for whether the respondent classifies himself/herself as being on the left of the political spectrum. The question is formulated as follows: "In political matters, people talk of left and right. How would you place your views on this scale, generally speaking?" The respondent is given a scale 1 to 10,1 being the most leftist. We classified as leftist anyone who answered with a score of 5 or below. All other individual characteristics are also from World Value Survey.

Absolute value of $t$ statistics in parentheses. * significant at $10 \%$;* significant at $5 \%$; ** significant at $1 \%$. 


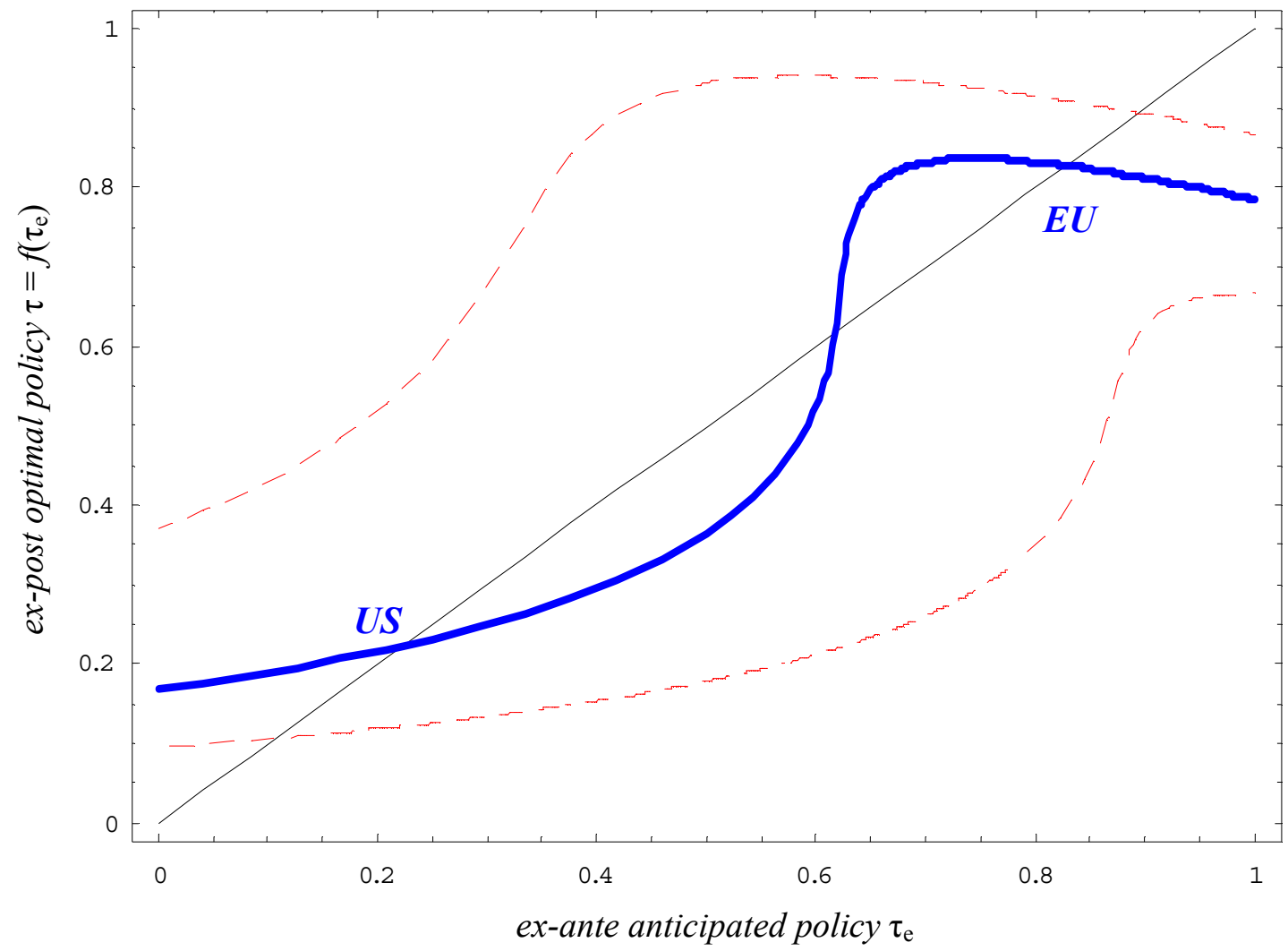

Figure 2

The figure depicts the relation between the tax rate that agents anticipate ex ante (horizontal axis), and the tax rate that the society finds optimal ex post (vertical axis). The solid curve represents an economy where the effect of luck is moderate as compared to talent and effort. An equilibrium corresponds to any intersection of this curve with the 45-degree line. There are two stable equilibria, one with low taxation, high inequality, and low injustice (US), and one with high taxation, low inequality, and high injustice $(E U)$. The lower dashed line represents an economy where the effect of luck is very small, in which case only the low-tax regime survives. Finally, the upper dashed line represents an economy where luck dominates, in which case only the high-tax regime survives. 